\title{
Effects of Various Behaviours in the Break Times between Learning
}

\author{
Takashi Ito ${ }^{1, *}$ and Kenichi Takahashi ${ }^{2}$ \\ 1 Department of Industrial and Systems Engineering, Aoyama Gakuin University, Sagamihara 252-5258, Japan \\ 2 Graduate School of Information Sciences, Hiroshima City University, Hiroshima 731-3194, Japan; \\ 6961643@hiroshima-cu.ac.jp \\ * Correspondence: ito@ise.aoyama.ac.jp; Tel.: +81-42-759-6421
}

Received: 8 July 2020; Accepted: 20 August 2020; Published: 21 August 2020

\begin{abstract}
E-learning provides users with the experience of learning at their own pace, without being restricted by time and place. Learners tend to get tired gradually during learning, and therefore, it is important to have breaks between studies to maintain learning performance. Furthermore, the break time has to be effective so that learners can refresh. This study compares three types of breaks: quiet, active, and communication breaks. In the experiment, university students in their twenties are asked to solve as many mathematical calculation problems as possible for $15 \mathrm{~min}$. The experiment comprises three learning sessions and two three-minute breaks between them. Learners are assigned one of the three types of breaks to refresh themselves. The effect of those resting behaviours on learning is examined, and the results are evaluated with regard to the accuracy of their calculations and their answering time. The effects of these behaviours will be discussed based on the experimental results and the questionnaire.
\end{abstract}

Keywords: rest time; concentration; e-learning; mathematical calculation

\section{Introduction}

E-learning is a proactive learning system that utilizes communication networks and information technology. In recent years, e-learning systems have been introduced in university lectures and company training. The diversification of devices used for learning, such as smartphones and tablets, as well as the fact that people can learn at their own pace, without the restriction of location and time, seem to push this spread of e-learning forward. Additionally, there are various benefits, such as the functions to learn repeatedly and be able to choose learning programs suitable to students' levels, the low cost, and the ease of managing learning data, such as learning progress and results of study [1]. While these various advantages are accelerating the spread of e-learning, there are also disadvantages. For example, as it is based on individual learning, subjects requiring practical skills that need instructors are difficult to give lectures to, and those who do not have a network environment and an information device cannot take courses in the first place. Furthermore, the biggest disadvantage is that it is difficult for learners to maintain concentration and motivation to learn. As mentioned above, many people learn individually, as they can study at their own pace, without being restricted by location and time. Thus, learners cannot communicate with the instructor and other learners. Their willingness to learn gradually declines and they cannot maintain the concentration. In order to solve these problems and promote student concentration in e-learning, we constructed a system with a function to praise and scold students, and a system using Kinect to measure the concentration of users and learning states while they learn [2-4].

Further, it is important to consider a break between learning for improving the learner's performance. There is research about how ways of spending the resting time affect performance of 
office workers using visual display terminals (VDT) [5]. In this research, they have referenced the Ministry of Health, Labour and Welfare of Japan guidelines for occupational health management of VDT office workers from April 2002 [6], such as "make sure that one continuous work time does not exceed one hour" and "have a 10-15 min break between consecutive works". It is shown that the work performance is actually improved by taking a break. In addition, a study focusing on mindfulness investigated the importance of switching moods during breaks within a workday [7]. The paper showed that employees need to separate their consciousness from their work for effective rest. Therefore, for e-learning, which uses VDT, it is necessary to take an appropriate break between learning sessions, within the limited time.

In this study, we investigated what kind of actions during break times maintain the concentration of learners and affect learning performance. This study compares three types of breaks: quiet, active, and communication breaks. The quiet break is a generally considered break action. This break includes three activities: "listening to music", "reading a book", and "doing nothing". In particular, "listening to music" is said to have a calming effect [8]. Thus, we expect that it would be possible to calm the learner's mind and maintain concentration. The active break implies playing two games with different characteristics [9]. This break cannot calm the learner's mind like quiet rest. However, learners can forget to study by playing the game. Thus, we expect that learners can learn with a new mood after this break. In the communication break, two kinds of communication robots [10] are used. This break refreshes the learner's mood like an active break. In addition, learners talk with the robot instead of doing something alone, so we expect that it is possible to refresh the mood with a small burden than the active break. The effects these resting behaviours have on learning is examined through experiments. The results are evaluated with regard to the accuracy of calculation and the answering time, and the effects of these behaviours are discussed based on the experimental results and the questionnaire.

\section{Related Work}

In related work, Miki et al. [5] and Qi et al. [11] have conducted a survey on breaks during tasks by using biometric information and showed the necessity for it.

Miki et al. have investigated effects of behaviours of breaks for office workers with VDT using information obtained from heart rate sensors and electro-oculography sensors. The experiment consists of two 15-min work phases and a 5-min break phase between them. In addition, to obtain accurate biometric information, 5-min phases for a calm mind is set at the beginning and end of the experiment. In the work phase, participants work on a calculation task assuming office work, and in the break phase, they conduct the break assigned from six types of breaks. There are six types of breaks to be considered: "drinking coffee", "exercising", "smoking a cigarette", "eating sweets", "sleeping", and "looking at a smartphone". In addition, participants wear a wearable heart rate sensor and eyeglasses with an electro-oculography sensor in order to acquire biological information. The experimental results showed that the average answer time after the break was significantly faster than the average answer time before break in the three behaviors of 'sleeping', 'exercising', and 'smoking a cigarette'. In addition, by combining and analyzing the average answer time and LF/HF (Low Frequency/High Frequency) value, which is a stress index obtained from heartbeat data, it had been shown that the average answer time is faster at state of stress. Thus, they thought that one is in a concentrated state when LF/HF value is greater than or equal to 2 . In our study, we have adopted more general behaviours because the participants were students.

Qi et al. investigated the mental fatigue of work using changes in brain activity taken by functional magnetic resonance imaging (fMRI). The experiment consists of two sections, "rest" and "no-rest", each section containing four tasks and three rests. In addition, participants were given an interval of one week during the two sessions. In the task (T) of this study, participants are required to ensure that they press the same button as the alphabet displayed in front of their quickly and accurately. This alphabet is selected from " $b$ ", "d", "p", and " $q$ " randomly. In the rest (R), they are required to rest while gazing at the white cross target displayed in front of them. The duration of each action is 5-min 
and $26 \mathrm{~s}$. The section of "rest" consists of R1-T1-T2-R2-T3-T4-R3, and the section of "no-rest" consists of R1-T1-T2-T3-T4-R2-R3. Participants performed these tasks in fMRI, and changes in brain activity of them were taken. The experimental results showed that the average correct answer rate of the task in the section of "no-rest" is lower than the average correct answer rate of the section of "rest". Thus, it is shown that the performance is reduced due to mental fatigue caused by continuous work. In addition, in the dynamic functional connectivity analysis using changes in brain activity, no significant results were obtained between $\mathrm{T} 2$ and $\mathrm{T} 3$, which were expected to have an immediate effect of rest. However, between $\mathrm{T} 1$ and T4, both main effects and interactions were significant. Thus, it is an important issue to examine behaviours of breaks suitable for work.

In addition, an influence of using social media during breaks on memory learning is attracting attention. Martini et al. have investigated effects of using social media immediately after learning [12]. In learning of this study, native German students memorise pairs of Irish and German words. Specifically, 20 word pairs are displayed in sequence for every $5 \mathrm{~s}$, and the learners will memorize these word pairs. In addition, when switching the displayed word pair, a phase of displaying a fixation cross for $3 \mathrm{~s}$ is inserted. After this learning, the learners immediately took the recall test. In the recall test, the learners are given a paper written with 20 Irish words in a random order, and they write German words corresponding to Irish words in $3 \mathrm{~min}$. Then, the learners take the break assigned from "rest with closed eyes" or "using social media". Finally, a recall test was conducted immediately after this break and one day. Experimental results show that the group with "using social media" exhibited an increased forgetting rate of words, and new visual stimuli, such as watching texts and movies, reduce memory retention.

\section{The Behaviours in Break Times}

In this study, we investigated and compared three roughly divided types of breaks. The first type is a quiet break, comprising activities such as "listening to music" or "reading a book". The second type is represented by an active break, characterised by moving one's body within a game, and the third is the communication break, in which participants interacted with communication robots. This section describes these three types of breaks.

\subsection{Quiet Breaks}

For quiet breaks, in this study, we considered three kinds of actions: listening to music, reading a book, and doing nothing.

In "listening to music", learners listened to music that they had prepared for themselves. It is known that classical music and the sound of music boxes are effective in relaxing a person $[8,13]$, but we did not limit the options to these genres in this study. Thus, learners could listen to the music of their choice at that time, as we thought that listening to their favourite music would be effective in the short breaks between studies.

In "reading a book", learners read a book during their break. As with the "listening to music" activity, learners could read books they had prepared for themselves. The length of the breaks was communicated to learners in advance; thus, they prepared the books they wanted to read within that time.

In "doing nothing", learners did nothing but look at a countdown that appeared on a screen. They could not take naps, sit with their eyes closed, or do ample body movements.

\subsection{Active Breaks}

The second type of break was the active break, in which learners relaxed by moving their bodies through playing games. We had prepared two games with different characteristics for them.

The first game was a shooting game, called the "fly-tapping game". An example of the game screen is shown in Figure 1. The objective of this game is to shoot down as many enemies as possible within the time limit. This game uses a 3D positioning device for an input device. The player holds 
the sensor in his hand and aims to the enemy by moving it vertically and horizontally in relation to the screen. In addition, the player can fire a gun by shaking the sensor back and forth and damage enemies that are hit. There are multiple types of enemies, and the player can acquire more points by defeating a rare enemy.

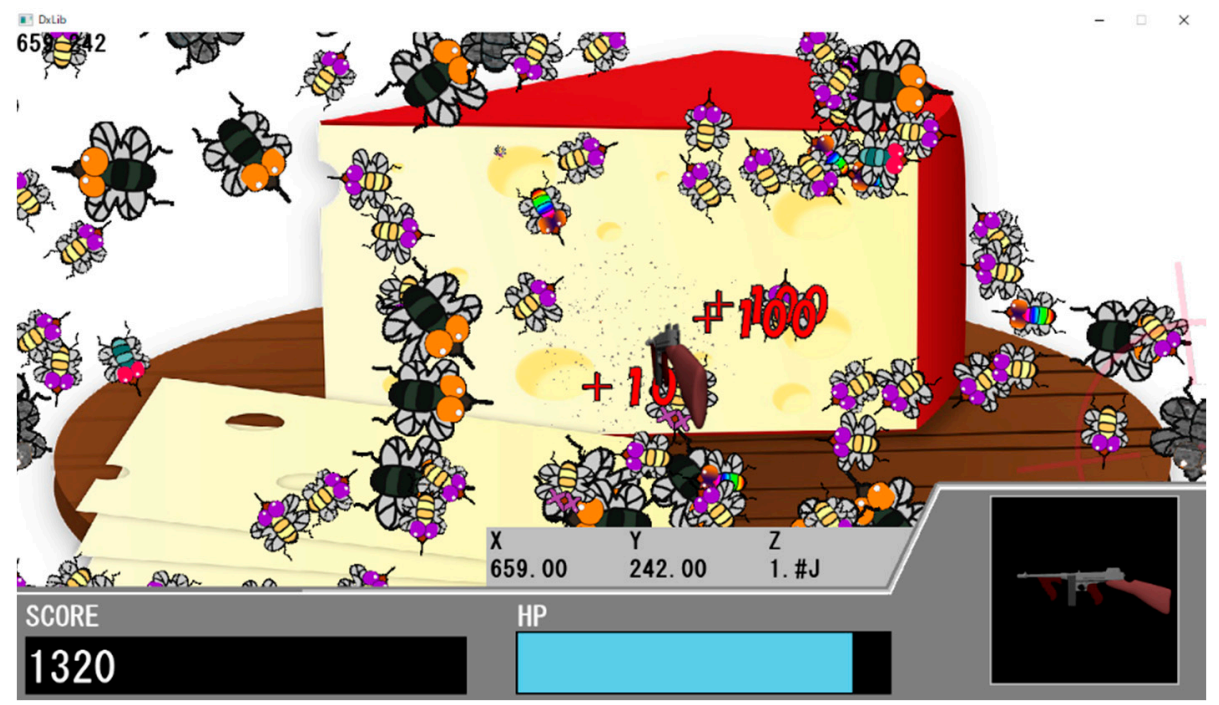

Figure 1. Screenshot exemplifying the "fly-tapping game".

The second game is a simulation game in which the player has to take care of a dog. A screenshot of the "dog-care game" is shown in Figure 2. A data glove is used as an input device. The player wears the glove on the non-dominant hand and selects an action icon by opening and closing each finger to change its state. Players can perform four kinds of actions: scolding, calling, feeding, petting. Players can move the action icon using a mouse held with the dominant hand. All the action icons, except for "calling", affect the dog when they are placed on it. The dog has mood and satiety parameters. Players can check those states by looking at the top of the screen. In addition, there is a hidden parameter, "taming", which is increased by keeping the other two parameters at their best. When the taming parameter is at a high state, the dog reacts to players' calls.

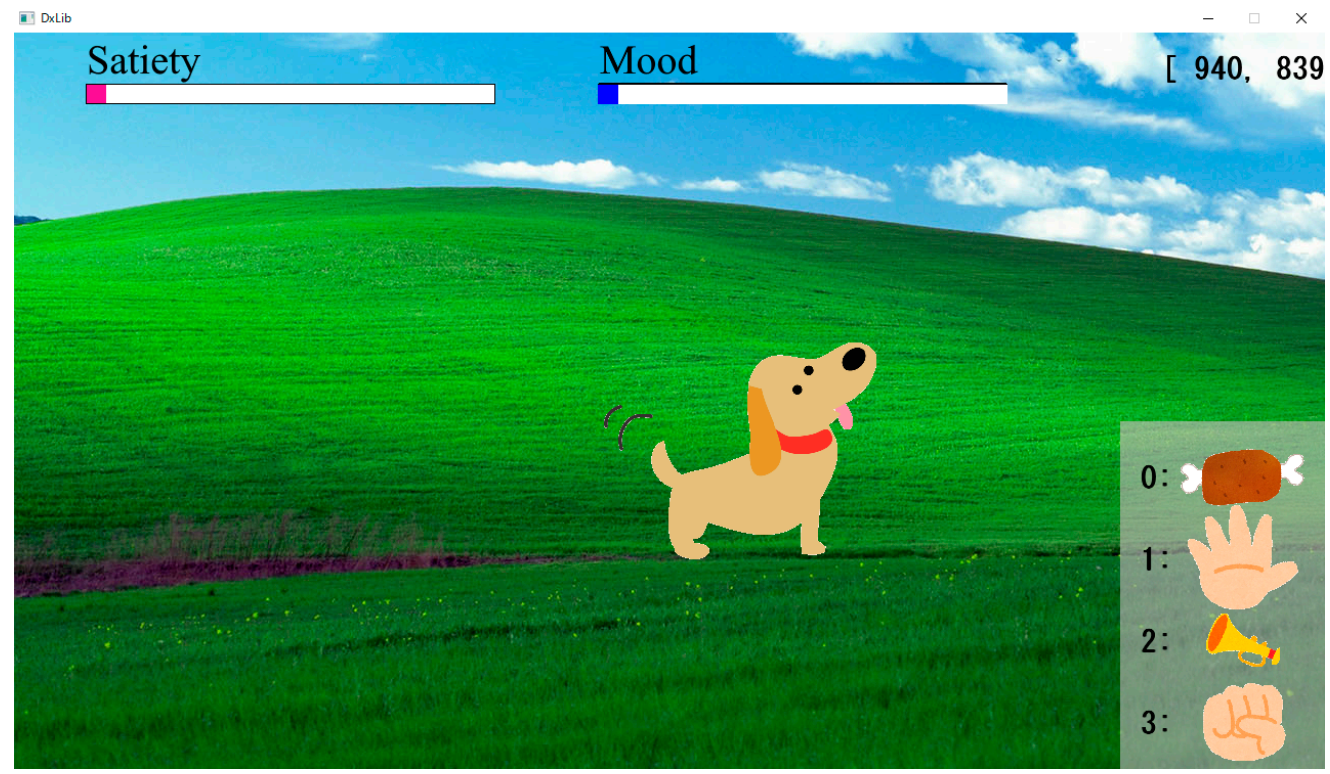

Figure 2. Screenshot exemplifying the "dog-care game". 


\subsection{Communication Breaks}

During communication breaks, leaners refreshed themselves using communication robots developed for two-way communication, such as dialogue and conversation with humans. Taking advantage of their characteristics, these robots are being researched as a conversation partner with seniors [14], systems to support schizophrenic patients [15] and tools to practice communication for children with autism [16]. We have prepared two types of communication robots for these breaks.

The first communication robot is a smart robot, "RoBoHoN", developed by Sharp Corporation [17]. RoBoHoN is a humanoid robot of a total length of about $19.8 \mathrm{~cm}$, and has the function of a smartphone. In addition, it supports 4 th generation mobile communication systems. RoBoHoN can not only work as a smartphone but also communicate with a user and play communication games. In addition, the user can add behaviours to RoBoHoN by using the "Scratch Pack for RoBoHoN". We added three behaviours: "raise a flag", "answer a riddle", and "guess who-I-am". We refer to these behaviours, including "enjoy dancing", which is one of the standard behaviours, as "playing with RoBoHoN". To activate a behaviour while playing with RoBoHoN, the user gives commands, such as "let's play raise a flag" or "enjoy dancing".

The four behaviours are described as follows:

(1) Raise a flag: In this game, the user raises a red or white flag in accordance with a command spoken by RoBoHoN. The user can execute four actions: raising the red flag, dropping the red flag, raising the white flag, and dropping the white flag. These actions could be taken through the input of the keyboard connected to RoBoHoN, by assigning a corresponding key to each. For example, if RoBoHoN says "Raise a red", the player has to press the key corresponding to raising the red flag. In the case of a correct answer, RoBoHoN moves the flag according to the spoken command, making it a visually enjoyable game.

(2) Answer a riddle: The user hears the riddle told by RoBoHoN and gives the answer verbally. If the user misses the spoken riddle, they tell "please say that again" to RoBoHoN, who will say the riddle again. We had programmed five riddles, and RoBoHoN randomly chooses which one to say.

(3) Guess who-I-am: The learner guessed what or who RoBoHoN was from spoken hints that it provided. RoBoHoN pretended to be an object, a person, or an animal. Upon hearing a hint (for example, "I am humanoid"), the learner made a guess. If the guess was correct, the game ended. If it was incorrect, RoBoHoN provided another hint. If the learner did not guess correctly after a certain number of hints, the game was considered over.

(4) Enjoy dancing: In this behaviour, RoBoHoN danced while playing music. More than 20 dance numbers were programmed and performed randomly. If requested, RoBoHoN performed a specially designed dance form "Koi dance".

The second robot was an autonomous entertainment robot, "aibo", developed by Sony Corporation. The aibo is a puppy-shaped robot with a total length of about $30.5 \mathrm{~cm}$. We considered that it would be effective to have learners interact with small animals while resting and adopted aibo. In fact, it was demonstrated that when workers view photos of small animals, such as kittens and puppies, during break times, their work efficiency improves more than by removing small pieces from holes in a game board and searching for specific characters in character strings [18]. Thus, we decided on "playing with aibo" as a break activity, using a robot that imitates a puppy.

While repeatedly interacting with people, aibo changes its behaviour gradually in accordance with the interactions [19]. The aibo used in this study is the latest version, which is equipped with artificial intelligence and network functions, such as facial recognition for up to 20 people, analysis of collected data in the cloud, and online backup of data. As aibo is equipped with a voice microphone and multiple touch sensors, a user can get the experience of touching an actual puppy. The aibo used in the study had learned some habits, such as "sit" and "paw", in advance. In addition to the basic actions, it may perform actions that a normal dog does not do, such as singing and dancing. 


\section{Mathematical Calculation}

In this research, participants studied using the e-learning system "Let's Study Offline" developed in our laboratory. This system can give memorization problems of English words and calculation problems using mathematical formulas. However, in this study, we focused on the calculation problems for investigation.

The learning screen for a calculation problem with mathematical expressions is shown in Figure 3. In solving the problem, the learner calculates using formulas composed with the four arithmetic operations, which are presented one after another. The learner looks at the formula on screen and calculates the number that fits in the square. Subsequently, the learner selects one suitable answer from the four choices below the exercise. When the answer button is pressed, the next calculation problem will immediately be displayed. The bottom of the screen displays the time remaining until the break. Whether the answers are correct is summarized at the end of each session.

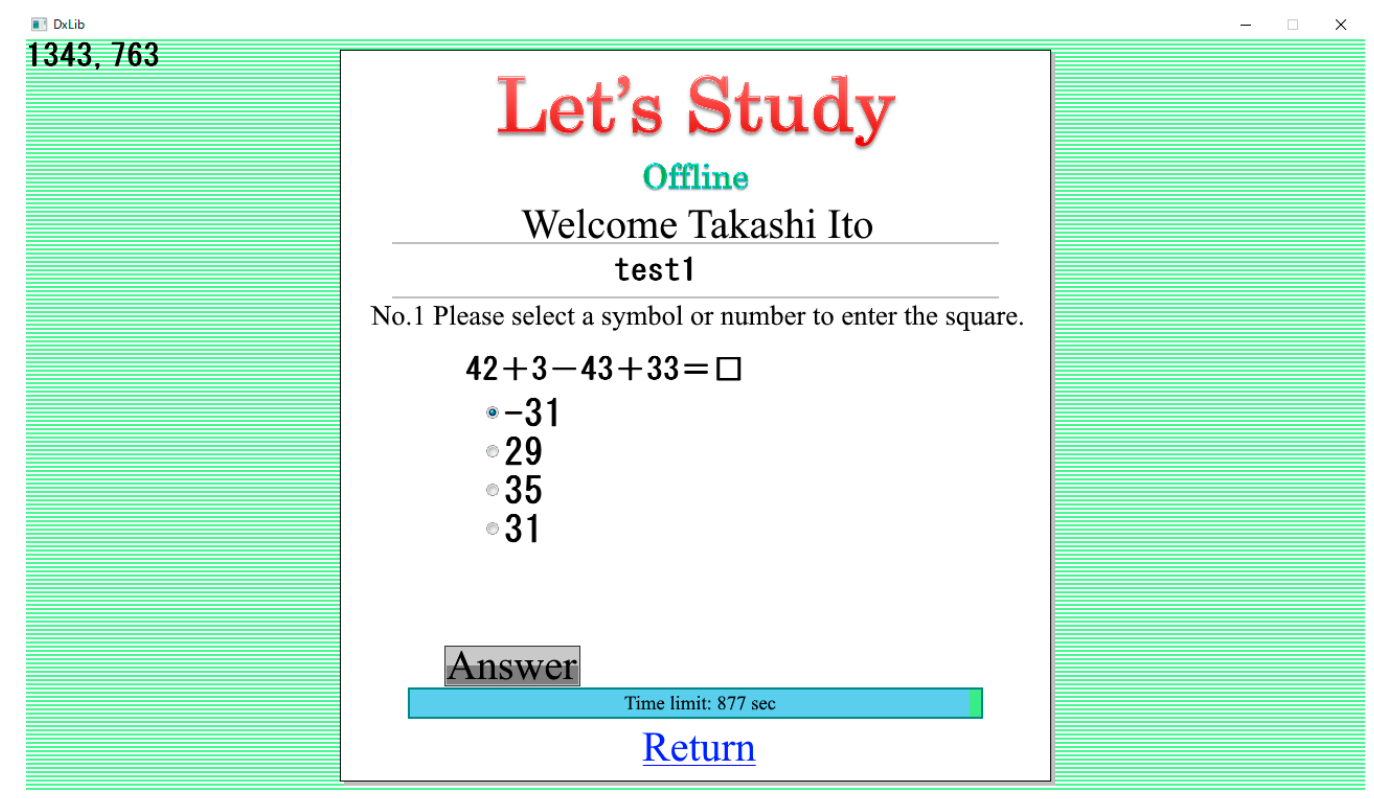

Figure 3. A page for mathematical calculation.

\section{Experiments}

\subsection{Experimental Outline}

This experiment comprises three learning sessions and two break sessions, as shown in Figure 4. In the learning session, participants answer the above-referenced type of mathematical calculation problems continuously for $15 \mathrm{~min}$. Subsequently, the answer results are displayed on the screen, and a few seconds later, the break session starts. During the break, learners perform the activities assigned to each group, for $3 \mathrm{~min}$. There are two break sessions in this experiment, and each group repeats the assigned activity both times.

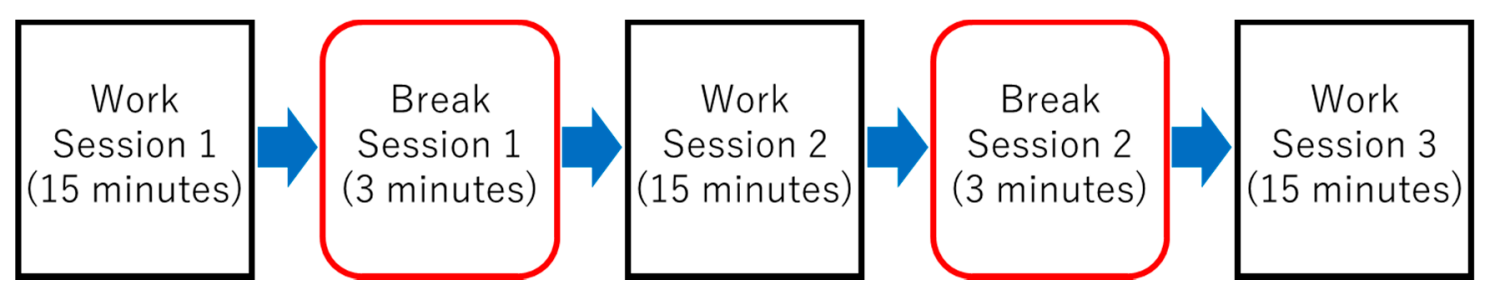

Figure 4. The flow of the mathematical calculation experiment. 
The participants in this experiment were students of our university in their twenties, and a total of 78 data sets have been collected. Table 1 shows the behaviours during breaks and the number of participants in each group $(G)$. In the grouping, the participants were asked to perform a mathematical calculation for $15 \mathrm{~min}$ as a preliminary experiment, and we performed the grouping by using their score. The participants were assigned so that the average score for each group is equal. In addition, in grouping for the communication break, we conducted a questionnaire asking "do you keep a dog?", and also considered this result.

Table 1. The behaviours during the breaks and number of data in each group.

\begin{tabular}{ccc}
\hline & The Contents of Behaviours & The Number of Data \\
\hline Group 1 (G1) & listening to music & 13 \\
Group 2 (G2) & reading a book & 12 \\
Group 3 (G3) & doing nothing & 18 \\
Group 4 (G4) & a fly-tapping game & 12 \\
Group 5 (G5) & a dog-care game & 13 \\
Group 6 (G6) & playing with RoBoHoN & 5 \\
Group 7 (G7) & playing with aibo & 5 \\
\hline
\end{tabular}

\subsection{Experimental Results}

Figure 5 shows the average correct-answer rate for each session for each group. The vertical axis is the average correct-answer rate, and the unit is percent. As a result of performing a T-test at a significance level of $5 \%$ in the correct answer rate of two work sessions before and after the break, no significant result was obtained in any group. Figure 6 displays the average answer time for each session for each group, and the vertical axis shows the average answer time for one question, in seconds. As a result of performing a T-test at a significance level of $5 \%$ in the answering time of two work sessions before and after the break, no significant result was obtained in most groups. Significant results were obtained in session 1-2 of the group of "listening to music" and session 2-3 of the group of "a dog-care game".

Regarding the groups assigned to have quiet breaks, G1, G2, and G3, we can confirm that the "doing nothing" group (G3) had the highest average correct answer rate (see Figure 5). Furthermore, G3 is the most suitable break behaviour among the three, as there was little difference in the mean answer time (see Figure 6). As for "listening to music" and "reading a book", it is likely they were not able to produce their respective effects in the short three-minute break.

From the groups having active breaks, G4 and G5, the "dog-care game" group (G5) showed a higher average correct answer rate than the group playing the "fly-tapping game" (G4), as shown in Figure 5. If we look at the slope of the graph, we can see that the trend is exactly the opposite. Figure 6 shows that the average answer time for G4 is shorter than that of G5; however, there is no difference between the first two sessions regarding G5. We thought that the fly swatting game was suitable for a change of pace, but the intense movement might have made the participants tired. Thus, we considered that the G5 activity is suitable as an active behaviour in this study.

Related to the communication breaks of G6 and G7, Figure 5 shows that the average correct answer rate for "playing with RoBoHoN" (G6) was higher than that for "playing with aibo" (G7). Thus, we considered that G6 had a suitable behaviour during break. On the other hand, the correct answer rate of G7 was low at first; however, it improved from session 1 to session 2 and maintained the rate thereafter. Regarding the average answer time presented in Figure 6, the difference in time for G7 is small, which suggests that G7 is more effective in maintaining concentration.

Examining the whole of Figures 5 and 6, it is shown that breaks with intense movement were not suitable for maintaining concentration. In addition, the breaks in which the "dog-care game" was played (G5) showed a similar trend with the ones "playing with aibo" (G7). Further, the correct answer rate for both groups was maintained until the end. These results showed that playing with small animals was effective in maintaining concentration. 


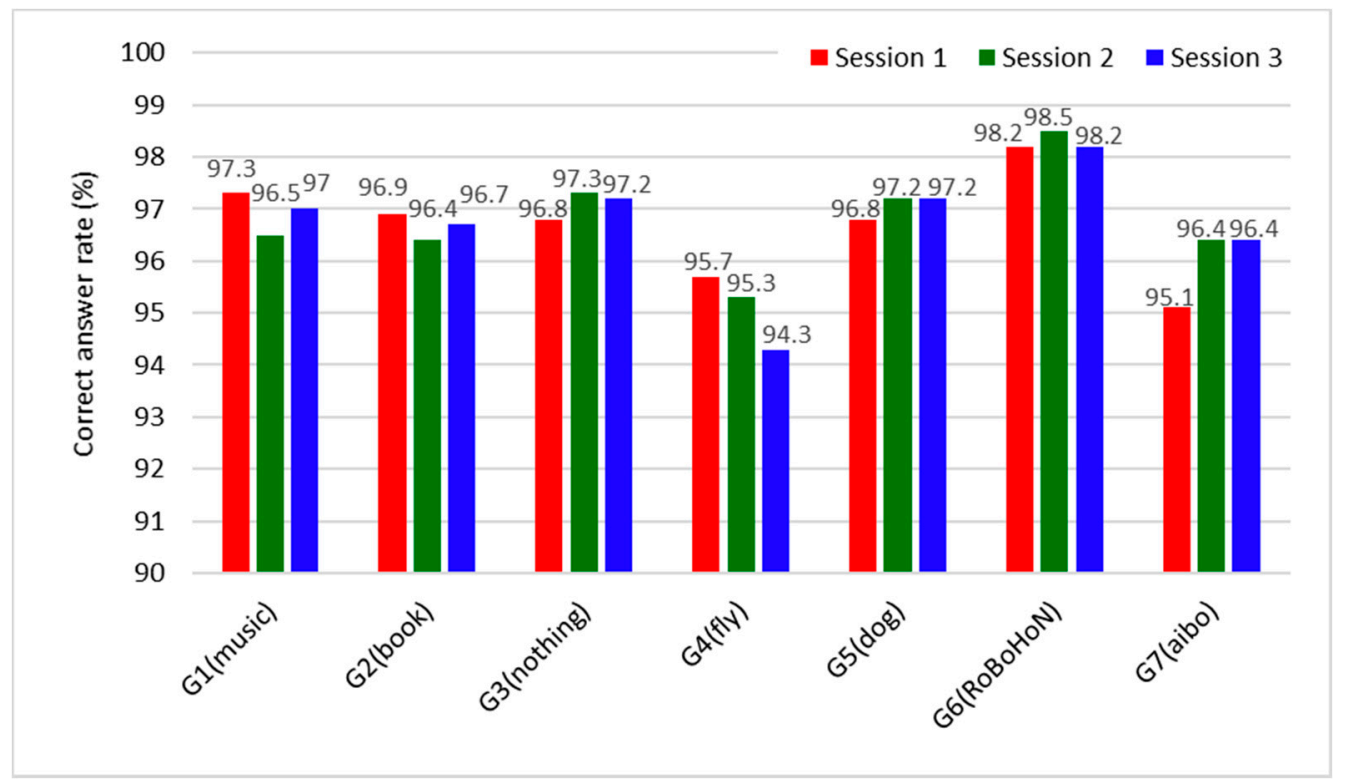

Figure 5. Average correct-answer rate for each session in groups.

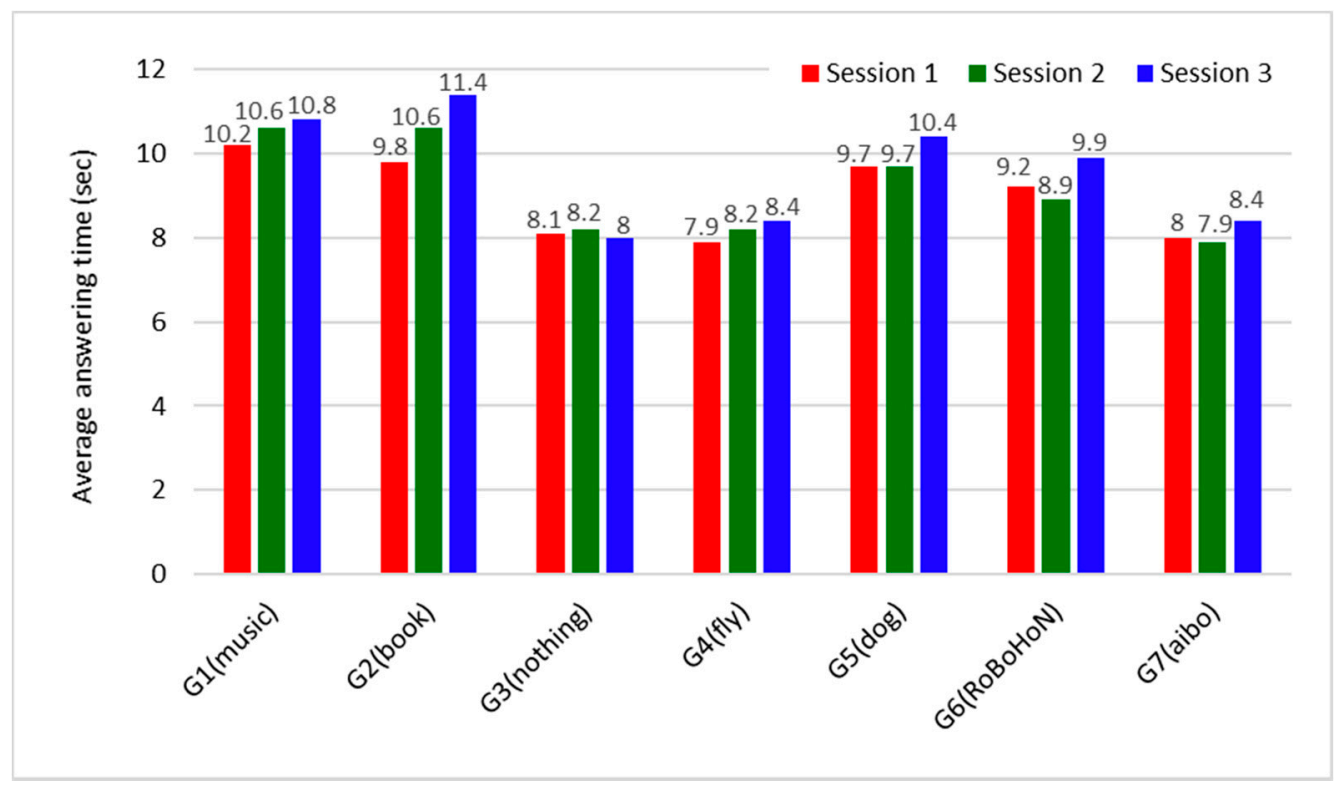

Figure 6. Average answering time for each session in groups.

\subsection{Questionnaire}

After the experiment, we asked the participants to complete a descriptive questionnaire and to respond to three statements by selecting responses on a five-point scale $(5=$ strongly agree to $1=$ strongly disagree).

Table 2 lists the evaluation items and the average scores for the seven groups. For groups six and seven, we did not ask the question corresponding to number six; thus, Table 2 does not provide answers to this question for the two groups. As the table shows, the highest score is 4.5, given by G1 for items five and six. The participants "listening to music" felt refreshed, and their concentration improved more than by the other resting actions, although the performance degraded. From the answer in the description format, we infer that they felt a three-minute break time was too short. The next highest score was 4.0, given by G6 and G7, which had breaks with communication robots. Thus, we have observed that breaks stimulating the sense of hearing are effective for refreshing the mood. G3 and 
G5 show high scores for items five to eight. The scores of G3 for items one to three increased as the sessions progressed, and they considered three minutes appropriate for break time. The scores of the "fly-tapping game" group for items one to three decreased. In the description format, there were several comments saying they were tired and the game did not refresh them. G7 shows a high score for item seven but a low one for item eight. Thus, we can consider that three minutes is too short for "playing with aibo", although it is a suitable action during a break.

Table 2. Average scores in the questionnaire.

\begin{tabular}{|c|c|c|c|c|c|c|c|c|}
\hline No. & Statement & $\begin{array}{c}\text { G1 } \\
\text { (Music) }\end{array}$ & $\begin{array}{c}\text { G2 } \\
\text { (Book) }\end{array}$ & $\begin{array}{c}\text { G3 } \\
\text { (Nothing) }\end{array}$ & $\begin{array}{c}\text { G4 } \\
\text { (Fly) }\end{array}$ & $\begin{array}{c}\text { G5 } \\
\text { (Dog) }\end{array}$ & $\begin{array}{c}\text { G6 } \\
\text { (RoBoHoN) }\end{array}$ & $\begin{array}{c}\text { G7 } \\
\text { (Aibo) }\end{array}$ \\
\hline 1 & I concentrated in the 1st session. & 3.8 & 3.3 & 3.7 & 4.3 & 3.8 & 3.8 & 3.4 \\
\hline 3 & I concentrated in the 3 rd session. & 3.8 & 3.0 & 4.2 & 3.7 & 3.7 & 3.0 & 3.6 \\
\hline 4 & $\begin{array}{l}\text { I kept my concentration throughout } \\
\text { the entire work. }\end{array}$ & 3.8 & 3.2 & 4.0 & 3.0 & 3.6 & 2.6 & 3.6 \\
\hline 6 & $\begin{array}{l}\text { I felt that the resting behaviour } \\
\text { improved my concentration. }\end{array}$ & 4.5 & 3.2 & 3.8 & 3.2 & 3.7 & - & - \\
\hline 7 & The resting behaviour was effective. & 3.0 & 3.2 & 3.5 & 2.7 & 3.2 & 3.0 & 4.0 \\
\hline 8 & The length of break was appropriate. & 2.5 & 3.3 & 3.9 & 3.7 & 3.4 & 2.8 & 2.6 \\
\hline
\end{tabular}

\section{Conclusions}

We conducted an experiment in which e-learning students assume one of the available resting behaviours during study breaks to investigate the effect of those behaviours on motivation to learn.

We found that quiet breaks were able to calm the learner's mind and maintain concentration in the break of learning activities such as calculation problems. In particular, both "listening to music" and "doing nothing" showed better results than "reading a book", because in these breaks, learners were able to calm down without thinking. In addition, there was an answer that the break time was too short in the questionnaire, and it was suggested that the effect of this break is affected by a change of the length of the break time. For the results of the experiment, we showed that active breaks are not suitable for break of learning such as a calculation problem because the learners become tired. However, leisurely games like the "dog-care game" were able to moderately refresh the learner's mood. Communication breaks were able to refresh the leaner's mood without putting too much strain on the learners. In particular, communication with a humanoid robot showed a high rate of correct answers, indicating that it is suitable for a break in this experiment. In addition, "playing with aibo" and "dog-care game" showed similar experimental results, demonstrating that contact with small animals is effective in maintaining concentration.

In this study, grouping was performed so that the average correct answer rate in the preliminary experiment was even, so we have thought that individual differences affect the answer time. Therefore, we could not support research results that the answer time was faster in the stressed break as Miki et al. [5]. However, In A, which is considered to be the most stressed, there is little change in the average answer time in group of "fly-tapping game" that is considered to be the most stressed, so it may be related to their results. In addition, the group of "fly-tapping game" has shown the lowest concentration from Figure 5. Although it was one of the breaks, it involved tasks similar to work when comparing with other breaks. Thus, we thought that a degree of concentration in group of "fly-tapping game" was caused by the continuation of the work as Qi et al. [11]. Furthermore, although the task of this study cannot be directly compared because it is a mathematical calculation, we considered that strong external stimuli while the break has some influence on learning as shown by Martini et al. [12]. Thus, we thought that "doing nothing" showed good results on average. Finally, robot therapy has been attracting attention in recent years, and utilization of robots has been researched as a conversation partner with seniors [14] and treatment methods for children with various disabilities [16]. In our research, robots were adopted as the conversation partner to change the mood during a break. 
The groups of using them were able to maintain their concentration continuously, the result has suggested that the robot has a healing effect.

In our future work, we perform experiments with more participants to improve the accuracy of the effects. In addition, we would like to consider "playing with actual animals" and "dialogues between people" as the behaviours in Break times. And, we will change the length of study time and rest time, and also investigate the appropriate rest time for various tasks.

Author Contributions: T.I. performed experiments, analyzed data, and drafted the manuscript. K.T. supervised the structure of this paper and the analysis results. All authors have read and agreed to the published version of the manuscript.

Funding: This research received no external funding.

Conflicts of Interest: The authors declare no conflict of interest.

\section{References}

1. Merits and Demerits of Introducing E-Learning. Available online: http://www.pro-seeds.com/trend/ meritdemerit.html (accessed on 13 May 2020). (In Japanese).

2. Takeue, M.; Shimada, K.; Takahashi, K.; Inaba, M. Experiments of displaying images to keep the motivation in e-learning. In Proceedings of the 2012 IEEE International Conference on Systems, Man, and Cybernetics (SMC), Seoul, Korea, 14-17 October 2012; pp. 120-125.

3. Ito, T.; Kotake, S.; Takahashi, K.; Inaba, M. Detecting Concentration of Students Using Kinect in E-learning. In Proceedings of the 5th IIAE International Conference on Intelligent Systems and Image Processing 2017 (ICISIP 2017), Honolulu, HI, USA, 7-12 September 2017; pp. 450-456.

4. Ito, T.; Kamiya, K.; Takahashi, K.; Inaba, M. A method for identification of students' states using Kinect. In Proceedings of the 13th International Conference on Ubiquitous Information Management and Communication (IMCOM 2019), Phuket, Thailand, 4-6 January 2019; pp. 341-350.

5. Miki, T.; Terada, T.; Maeda, T.; Karasawa, H.; Adachi, J.; Tsukamoto, M. Research of the effects of the break time on work performance. IPSJ SIG Tech. Rep. 2018, 2018-UBI-57, 1-8. (In Japanese)

6. Guidelines for Occupational Health Management in VDT Work. Available online: http://www.mhlw.go.jp/ file/06-Seisakujouhou-11200000-Roudoukijunkyoku/0000184703.pdf (accessed on 13 May 2020). (In Japanese)

7. Chong, S.; Kim, Y.J.; Lee, H.W.; Johnson, R.E.; Lin, S.-H.J. Mind your own break! The interactive effect of workday respite activities and mindfulness on employee outcomes via affective linkages. Organ. Behav. Hum. Decis. Process. 2020, 159, 64-77. [CrossRef]

8. Labbé, E.; Schmidt, N.; Babin, J.; Pharr, M. Coping with stress: The effectiveness of different types of music. Appl. Psychophysiol. Biofeedback 2007, 32, 163-168. [CrossRef] [PubMed]

9. Ito, T.; Takahashi, K. Experiments on Effects of Behaviours in the Rest Time between Learning. In Proceedings of the 9th Edition of the New Perspectives in Science Education Conference (NPSE 2020), Florence, Italy, 19-20 March 2020; pp. 216-221.

10. Yasumura, Y.; Ito, T.; Takahashi, K.; Kajiyama, T. Effects on Concentration of Different E-Learner Resting Behaviors in Reponse to Communication Robot Actions during Break Times. In Proceedings of the 14th International Conference on Ubiquitous Information Management and Communication (IMCOM 2020), Taichung, Taiwan, 3-5 January 2020; pp. 1-5.

11. Qi, P.; Gao, L.; Meng, J.; Thakor, N.; Bezerianos, A.; Sun, Y. Effects of Rest-Break on Mental Fatigue Recovery Determined by a Novel Temporal Brain Network Analysis of Dynamic Functional Connectivity. IEEE Trans. Neural Syst. Rehabil. Eng. 2019, 28, 62-71. [CrossRef] [PubMed]

12. Martini, M.; Heinz, A.; Hinterholzer, J; Martini, C.; Sachse, P. Effects of wakeful resting versus social media usage after learning on the retention of new memories. Appl. Cogn. Psychol. 2020, 34, 551-558. [CrossRef]

13. Ueda, Y.; Kashiba, H.; Ishii, M.; Yanagida, T.; Kitamura, Y.; Saeki, Y. Sound effect of a music box on EEG. J. Int. Soc. Life Inf. Sci. 2000, 18, 269-275.

14. Petersen, S.; Houston, S.; Qin, H.; Tague, C.; Studley, J. The utilization of robotic pets in dementia care. J. Alzheimer's Dis. 2017, 55, 569-574. [CrossRef] [PubMed]

15. Ozeki, T.; Mouri, T.; Sugiura, H.; Yano, Y.; Miyosawa, K. Use of communication robots to converse with people suffering from schizophrenia. ROBOMECH J. 2020, 7, 1-14. [CrossRef] 
16. Kumazaki, H.; Muramatsu, T.; Yoshikawa, Y.; Matsumoto, Y.; Ishiguro, H.; Sumiyoshi, T.; Mimura, M.; Kikuchi, M. Comedic experience with two robots aided a child with autism spectrum disorder to realize the importance of nonverbal communication. Psychiatry Clin. Neurosci. 2019, 73, 423. [CrossRef] [PubMed]

17. Sharp to Release RoBoHoN Mobile Robotic Phone. Available online: http://global.sharp/corporate/news/ 160414.html (accessed on 13 May 2020).

18. The Power of Cute: How Looking at Pictures of Baby Animals Can Help Improve Your Concentration Levels. Available online: https://www.dailymail.co.uk/news/article-2210614/The-power-cute-How-looking-picturesbaby-animals-help-improve-concentration-levels.html (accessed on 13 May 2020).

19. Aibo. Available online: https://us.aibo.com/ (accessed on 13 May 2020).

(C) 2020 by the authors. Licensee MDPI, Basel, Switzerland. This article is an open access article distributed under the terms and conditions of the Creative Commons Attribution (CC BY) license (http://creativecommons.org/licenses/by/4.0/). 